\title{
PSYCHOLOGICAL VULNERABILITIES OF INTERNALLY DISPLACED PERSONS IN PAKISTAN AND ITS EFFECTS ON GENERAL COMMUNITY
}

\author{
Abdur Rahman Aleemi ${ }^{1}$ \\ Dr. Muhammad Tariq Chaudhry ${ }^{2}$ \\ Muhammad Azeem Qureshi ${ }^{3}$ \\ Institute of Business \& Technology, Karachi \\ Dr. Roomana Anwar ${ }^{5}$ \\ Baqai Medical University, Karachi
}

\begin{abstract}
Purpose: The purpose of this study is to assess the effects of psychological problems faced by IDPs (displaced as a result of Operation Zarb-i-Azb) of North Waziristan on local Community. IDPs coming from Waziristan and surroundings including men and women of all ages and childeren are the ones who are more vulnerable to physical and mental stresses likely to be caused by military actions of terrorists and counteraction by Pakistani Armed Forces. They have residence in shelter homes, tents are in a community which is different and most of the time hostile from their own community. The stresses like violence, migration, imposed poverty unhygienic and unsystemic living atmosphere of camps lead the IDPs to a change in everyday life activities away from their own cultural routines which in turn is causing deterioration of society as well.
\end{abstract}

Methodology/Sampling: This is primarily an exploratory study done on the field in IDP camps situated in Bannu disctrict. We approached a sample of 500 IDPs and identified around 200 to be suffering from psychological issues, who were interviewd and and were administered with questionnaires with the help of trained surveryours and medical team.

Findings: It is noted that such transitory unplanned no systemic living has caused an increase in activities like thieving, use of drugs, abduction for ransom, and other forms of violence and such like activities. The relationship between psychological issues of IDPs and the effects on community (Proxied by Crime rate) were subjected to descriptive analysis and were found that significantly good number of IDPs suffers from psychiatric disorders and there is a significant increase in crime rate for areas with sufficient number of IDPs around.

Practical Implications: Displacement results in emergence of particular vulnerabilities for those affected, and also for the surrounding communities, thereafter necessitating specific measures for the provision of assistance and further protection corresponding to vulnerabilities.

Keywords : War on terror, internal displacement, resettlement, trauma, PTSD, psychological disorders, crime rate, Military Operation, Zarb-i-Azb.

\section{Jel Classification: D920, E220, F210}

* The material presented by the author does not necessarily portray the viewpoint of the editors and the management of the Institute of Business \& Technology (IBT)

\footnotetext{
1 Abdur Rahman Aleemi

2 Dr. Muhammad Tariq Chaudhry

3 Muhammad Azeem Qureshi : abdurrahmanjan@gmail.com

4 Dr. Roomana Anwar : azeem.qureshi@hotmail.com
}

(C) IBTJBS is published by the Institute of Business and Technology (IBT) Main Ibrahim Hydri Road, Korangi Creek, Karachi-75190, Pakistan. 


\section{INTRODUCTION}

For almost a decade now the land forces of Pakistan including Pakistan Army, Frontier constabulary, Police and other military, paramilitary as well as civil armed forces are present in Waziristan and surrounding areas and initiated a number of military operations against ingression of both imported as well as local settled terrorists. However the desired objectives seem to be elusive so far and the situation across the length of country specifically in the tribal belt of KPK kept worsening. The law and order situation, as a result deteriorated to an extent that people were forced to fall prey to the orders of local terrorist commanders. As a corollary, these circumstances left no option for Pakistan Armed Forces but to launch a decisive operation to finally nip the evil in bud through the recent operation(in Waziristan) launched on June 15, 2014 and was named Zarb-i-Azb.

Besides the cited benefits of this operation, it has also sparked humanitarian crises; that is the main tenet of this paper. It was May 2014, when an offensive military operation was launched against TTP. As a result, local people have to move out of the area and they moved in masses at an alarming rate. All sorts of transports from animal carts to buses to tractors were deployed for the purpose of such massive transition of population carrying with them just the essential belongings.

To start with the gigantic task of providing humanitarian assistance, IDPs were registered at different places; starting from Waziristan to Bannu where they were found and felt to be safe from the horrible catastrophes of war and fighting. It gradually turned to be a huge exercise simultaneously happening at FATA, Peshawar and so many other parts of KPK. The government propagates the total number of registered IDPs as 992,649 individuals (90,756 families): 256,272 males; 284,191 females; and 452,186 children. Statistics further indicate that above $74 \%$ amongst these IDPs are women and children. However, all national non-governmental as well as international agencies believe that those registered are not the only ones and actual number is much more than being announced by the government. Some say a number between 500,000 - 600,000 above the spoken numbers is more realistic.

However the recent displacement was not anything new for the people and government of Pakistan. In May 2009, more than 2 million people became internally displaced due to such similar fighting between security forces and militants in the valley of Swat. That was yet another largest internal displacement witnessed in recent history of the country. Displaced poured into their neighboring peaceful districts of Swabi and Mardan, Buner and Lower Dir to escape the fighting between Patriot forces and militants. This time again in 2014, IDPs from North Waziristan had no time but to grab only principal personal belongings before they could flee the battled area. They immediately required a shelter to hide, some food to live, an access to drinking water and health facilities. Further the severe scorching heat in plains and then the paralyzing cold in the mountains added to their miseries. The multiple traumas of conflict, displacement, poverty, unemployment, compounded by the loss of property, family members, uncertainty about the future and so much, when added all together resulted in widespread psychological 
Psychological Vulnerabilities of Internally Displaced Persons in Pakistan and Its Effects on General Community

and psychiatric issues amongst IDPs of all ages of both gender. However the delicate like women and children were worst to get affected.

The IDPs of Waziristan are far more exposed to the ill effects of psychological problems than other people settled in their houses. This incidence/prevalence is found to be high in all age groups of both genders. The negative impact of psychological problems of IDPs are correspondingly reflected on local community level and this study is intended to asses these in particular. This is a typical exploratory study and was conducted on the field to gain maximum insights of the miseries of the displaced people which to the best of our knowledge might be the first of its kind. The study is designed to achieve the following primary objectives;

a. To get familiarized with the incidence of major psychological disorders amongst IDPs of Waziristan.

b. To explore as how the psychological issues reflect on general masses or surrounding community.

c. To remind the government, national / international humanitarian aid agencies for the effective management of psychosomatic problems of IDPs.

d. To gain firsthand knowledge about the psychological miseries of IDPs.

The importance of this study is multifold as much is highlighted for the physical needs and medical requirements of IDPs of Waziristan. Although not sufficient but considerable is done to address their health needs. Hospitals and dispensaries are established, male and lady doctors are performing their holy role to alleviate their physical miseries. Some Gynecologists and Pediatricians have been engaged by Pakistan army and with the very limited access of local NGOs. But a horrifying, life long, self and others life threatening patients are still left alone. No good effort exists to explore the incidence of psychiatric illnesses amongst IDPs. This study will highlight various illnesses causing mental / psychiatric issues amongst internally displaced people. This study will further provide the first step to draw the attention of the concerned to the long lasting effects of psychiatric issues in such population.

The study will further help to identify the individual psychological impacts which in turn can cause collective community miseries and thereafter assist the sufferers to develop a "toolkit" of measures for dealing with such issues like anxiety, depression, fear, sadness and other emotional and psychological impacts. It will provide a combination of knowledge as what can happen to people who experience tragedy, and at the same time familiarize with the art and skills to successfully navigate and tackle the disaster victims' psychological impact.

\section{LITERATURE REVIEW}

Internal displacement has been around in different parts of the world since years. Much has been written to focus on their issues but literature finds little for the social determinants or the effects on general community of physical and mental health of IDPs who found it unavoidable to stay at their homes due to the fierce armed conflict but yet to shift within the parameters of international boundary of their country. The findings of studies from internal displacement in northern Uganda explored multiple 
key social determinants inter alia, Going through trauma which can result in "over thinking" which in turn causes "madness" because of worry, poverty, loss of freedom and uncertainty. Surprisingly about refugees, who crossed international borders, having been provided better support than IDPs (having limited support and protection under international law from UN as well as national governments) Fazel et al. (2005).Furthermore the participants were also found to have profound deterioration of the mental health among the displaced who may have faced the atrocities.

Research focusing at specific mental health outcomes of conflict zone living populations remained with the influence of geo-political, environmental, socio-economic, and cultural factors (Roberts et al. 2009). Similarly another cross-sectional multi-staged, random survey of 1210 adult IDPs provides confirmed clues of linkages between exposure to traumatic events and deprivation of essential goods and services suffered by IDPs with the accumulative effect of all these has upon their psychological health. Security, family and friends' assistance and psychological support were found to be the instant requirements to assist IDPs in northern Uganda to re-build their normal lives. Majority of the respondents fulfilled the criteria for Post Traumatic Stress Disorders (henceforth PTSD) with around (67\%) fulfilled symptom criteria for depression. Over half (58\%) reported multiple traumatic episodes as well (Roberts et al. 2008). On the very contrary (Makhashvili et al. 2014) reports a cross-sectional household survey of adult IDPs with few returnees from the conflict in the Republic of Georgian 1990; provided squeezed evidence on relationship between psychiatric diseases prevailing in conflict-affected populations. PTSD, delusions, illusions and hallucinations, depression, anxiety and disability measured by cut scores on Trauma Screening Questionnaire, Patient Health Questionnaire 9, Generalized Anxiety Disorder 7 and the WHO Disability Assessment Schedule 2.0., The probable prevalence of PTSD, depression, anxiety, and co morbidity amongst the 3,025 respondents came up as $23.3 \%, 14.0 \%, 10.4 \%, 12.4 \%$, respectively.

Similarly, a high prevalence of psychiatric illnesses and disability was found among conflict zone people of Georgia. It was also noted that people affected by fighting are more frequently influenced by traumatic events and daily stresses and remain at high risk of mental disorders (Miller \& Rasmussen, 2010; Steel et al, 2009). However, few studies suggested that levels of posttraumatic stress disorder recede with time, but the evidence remains sparse and unreliable specifically for displaced who have returned back to their home areas.

Similarly another perspective, the evidence on the use of alcohol amongst conflictaffected people remains very weak, despite huge speculations. Robert et al. (2014) tried to find if any pattern of alcohol use disorder prevails amongst war affected persons in Georgia and found that $71 \%$ men and $16 \%$ women were current drinkers in which $28 \%$ men and $1 \%$ women were labeled having hazardous alcohol use; and 12\% men and $2 \%$ women were episodic heavy drinkers. Significant features which could be related for both the outcomes were age and experience of having any serious injury. Cumulative trauma events and depression factors were also found having links with at least hazardous alcohol use.

As it is clear that IDPs are most vulnerable to all types of violence and daily normal 
Psychological Vulnerabilities of Internally Displaced Persons in Pakistan and Its Effects on General Community

life stressors, however IDPs report most of the psychological distresses much more, when compared to returnees and non-displaced peers. Mels et al. (2010) document that among 819 participants in Congo, most were affected by psychiatric illnesses followed by returnees, whereas non-displaced adults were the least affected. On further analysis the main mental illnesses found associated with the exposure of trauma included posttraumatic stress, internalizing and daily stressors which were not found among non displaced participants. One other important factor contributing towards these illnesses included death of close family member and absence of legitimate sex. In April 2011, a post-election violent conflict in northern Nigeria led to resettlement of internally displaced persons in a camp in Kaduna where 258 grown up IDPs were subjected to a survey. For Depression, Hopkins symptom checklist was used, for definite depression composite international diagnostic interview and for psycho-trauma; communal trauma event inventory, social provision scale for Social adjustment and Harvard trauma questionnaire for symptomatic PTSD were used. Multiple logistic regressions was adopted to determine exact position of the disease and was found that $154(59.7 \%)$ were having suspected depression and 42 (16.3\%) were having definite depression. It was also found that females were more severely affected by probable and definite depression (Sheikh et al. 2011).Similarly, 376 of the Bosnian refugees were interviewed for symptoms of PTSD and depression during 1996 and then 1999. A comparison was made of the 2 periods to find out the changed parameters. A persistent consistency was observed for both periods (Mollica et al. 2000). As per as the Pakistani experience is concerned, Hussain(2010) attributes psychiatric problems after recording of about 97,000 psychiatric cases from FATA, Swat, Tank, Hangu, Dara Adamkhel and other areas hit by violence. Later on, the number though reduced to around 22,000, including women and children, he finds this affected population being sufferer from severe PTSDs, in militancy-wracked areas because of fear, stress, coping with the murders of family and friends, and seeing mutilated bodies after terrorist attacks. Despite the fact that an overwhelming amount of literature is available on the psychological, psychiatric and other mental illnesses of the internally displaced throughout the world including Porter and Haslam (2005), Roberts et al. (2008; 2009 and 214), Bolton et al. (2007) among others. However to the best of our knowledge none has assessed the reciprocal effects of the psychological problems of IDPs on the general community. And this study is particularly designed with the purpose to fill this gap to assess that whether the psychologically distressed affects the surrounding community or not? If yes, then we will try to assess how, in what shape and form?

\section{RESEARCH METHODOLOGY}

\subsection{Study setting}

This study was conducted on filed in IDP camps from North Waziristan in KPK from September 2014 to December 2014. These camps are mainly located in Bannu and surroundings and are placed on the outskirts of the city in transit camps as well as in schools and other governmental buildings and compounds. A huge number of men, women and children of all ages are living in these camps whereas equal numbers are also settled in urban areas on rented accommodation or with relatives. However this study addresses and approaches the people settled in camps only. 


\subsection{Study design}

A cross-sectional multi-staged, random survey of 500men, women and children of all ages who were registered IDPs from North Waziristan was conducted during the months of September 2014 to December 2014. The study population included males, females and children of all ages. We defined IDPs as people living within the transit camps or temporary accommodations in schools and governmental buildings and displaced as a result of the violent conflict following the initiation of operation Zarbe Azab by Pakistan Armed Forces in mid 2014 in Waziristan and adjoining areas of KPK. However it should be noted that we excluded persons already diagnosed with a mental disorder prior to this period and those who refused consent.

\subsection{Data collection and procedure}

We recruited 5 data collectors who could speak Pashto and other local languages along with English fluently and had experience with data collection. They were trained for a period of five days on the use of the study questionnaire and interview techniques prior to the onset of the study. Data collection took place over a period of 30 days and the average duration of each interview was 40 minutes. Two supervisors (including the authors), a psychiatrist and a senior resident doctor supervised the data collection process.

To assess the effect of psychological problems of IDPs on the community, having no other option, we chose the crime rate as a proxy. Any increase in the crimes registered found in abundance due to the influx of IDPs is considered to be the result of these psychological issues of IDPs. IDPs were initially interviewed to ensure their origin and present status as well as their mental health and finally a questionnaire was distributed to be a participant of the study. Out of the 200 selected 34 could not be traced later as they probably shifted from their location where as 42 refused to participate further. 21 were those with whom effective communication could not be established despite having the services of a local translator mainly due to the social norms of IDPs' culture and administrative difficulties prevalent around IDPs camps. This left us IDPs from all ages, gender, tribes in different camps as well as those reported at different medical set ups were included in this study. The questionnaire was distributed attached as Annexure "A" not only to further confirm their social problems but mental status as well. Flexible questions were included so as to suit the respondent's answers, and prompts were provided as and when they felt requirement. These prompts included reference to the information provided in previous answers by the respondents themselves. The crime data was collected using information provided by different police stations in Bannu district, the main hub of IDPs. Due to their organizational and administrative working conditions the information was not numerically given but nevertheless the provided information gives a fair idea about the prevalent social and criminal state in the local society and about the increase / decrease encountered amongst certain crimes which could be linked with the influx of IDPs in the nearby vicinity of those Police stations. However a crisp quantitative data with exact origin and accused remains a noteworthy limitation of this study.

Levels of exposure to traumatic events and their link to different psychological / mental states were measured and thereafter analyzed using the Harvard Trauma Questionnaire and Hopkins Symptom Checklist-25 by Psychologists and Psychiatrists working in 
primary to secondary to tertiary healthcare set ups but not mentioned as they fall beyond the scope of this study. The resultant set of 103 participants and with the diagnosed mental issues is presented in table 1 and 2 (see appendix);

Table 1: Demographic Distribution of the Participants.

\section{FINDINGS AND RESULTS}

\subsection{Psychological Issues Faced By IDPS}

A rough estimate finds almost 5\% of the IDPs suffer from psychological problems that can snowball into a major public health issue if not quickly settled back to their native places. Hence it is believed that thousands of Pakistanis who have been displaced by military action against militants during recent times are destined to develop psychological ailments. Respondents actually also commented during interview as how they perceive conflict and displacement have led to changes from their original social and cultural norms however they are not found worth mentioning in the study. The mental illnesses are grouped as diseases with its prevalence amongst IDPs of North Waziristan in the table 2 below (see appendix);

Table 2: Psychological issues faced by IDPs

\subsection{Negative Impacts of Psychological Disorders on Community}

Mental/behavioral diseases impose a large impact on all tiers of society- individuals, families and communities as well. Prolonged violence has reshaped many lives. They have witnessed destruction, shelling and bloodiest scenes. All these are termed as the human aspects of the burden of mental disorders. They are difficult to assess and difficult to quantify as well; but nevertheless they cannot be overlooked or left alone. Families often find difficult to extract sufficient time to look after the mentally ill even if a family member. Furthermore the families also suffer economic and social losses as an individualhe or she is not productive any more.

This all has reshaped the trends of the local society in Banu and surroundings and the crimes in these areas have been increased since the influx of IDPs as shown in table 3 below:

We approached a total of 103 IDPs who were diagnosed as suffering from mental illnesses, 54 were male, 35 were women and 14 were children. The participants were in age from 9 to 72,32 being the average age. The participants were from different tribes, mostly Mehsuds and Waziris, all were Muslims. For the effect on community, crime rate was used as a proxy and the data were gathered from local Police stations. The resultant data is presented in table 3 (see appendix). A simplified table 4 (see appendix) is also provided for approximate estimation of increase in crime rate; however the exact number of crimes and the involvement of IDPs were not assessable. Table 3: Increase in crimes. Source; local police stations collected by the authors Table 4: Legend for table 3

As is evident from the data that significant increase in certain crimes has been observed which is a matter of deliberation for the fact that humanitarian agencies and the government have focused on physical ailments, but the mental challenges can grow into a chronic health issue and thereafter can be reflected upon community as social consequences and evils which may persist even after IDPs return to their native villages to restart their lives as is advocated in this study. The study highlights considerable 
impact of mental illnesses over community in the form of social crimes and disturbances. Limitations

1. This study was conducted in 3 months period which is quite short.

2. Administrative difficulties were encountered in data collection due to social norms as well as restrictions imposed by authorities.

3. Numerical values of criminal data could not be attained.

4. The same subject group having diagnosed suffering from mental illness was not involved with criminal data, neither vice versa.

5. Only IDPs living in the camps and those reports to medical set ups were included. Similarly criminal data available with Police station was analysed. We excluded those who were staying with relatives or have moved out of the camps for other reasons.

\section{CONCLUSIONS AND RECOMMENDATIONS}

This study was designed to assess the effects of psychological problems faced by the internally displaced on the general community. We conducted on field surveys in IDP camps with the help of the medical teams deployed in those camps including a psychiatrist and a senior resident medical doctor. Furthermore the data for different crimes were gathered from local police statations and was found to have a significantly increased after the influx of IDPs. This study might be the first of its kind particularly in the case of Pakistan, and as Pakistan is having a history of dealing with displaced people resulting from violent conflicts. Hence this study is having multifold significance for the authorities and humanitarian aid agencies to understand and gain insights to this particular dimension of displacement and the associated communal effects.

Displacement from their native place results in emergence of particular vulnerabilities for those affected, and also for the surrounding communities, thereafter necessitating specific measures for the provision of assistance and further protection corresponding to vulnerabilities. The effects of displacement are found to be more severe on the most vulnerable and marginalized people. Children, in particular lack food as food is not sufficient for families and in package children have been neglected. Their priorities include protection of life and property, food and feed, shelter, health and sanitation, water, fans, solar system, hygiene kits etc.

Similar problems exist in men and women of all ages as per their age and gender distribution. However a horrifying prolonged health issue which still has not been notified as per its intensity and prevalence are the psychological health problems. In this regard, the influence of armed conflict on mental health reflected in society as crime has been noted as indirect but strong. Humanitarian assistance and that too very immediate and instantly is crucial for IDPs, but the focus should not get restricted to just emergency response instead must move well beyond to encircle all remote needs. Physical and mental health both must be focused in addition to social and economic requirements of IDPs. The IDPs have certain very specific needs throughout the various phases of displacement and their needs in routine continue long after they return back to their homes.

IDPs that remain within the territorial jurisdiction of their own counties, it comes out to be the primary duty and responsibility of government to provide protection and humanitarian assistance to this population without any discrimination. This is in 
Psychological Vulnerabilities of Internally Displaced Persons in Pakistan and Its Effects on General Community

accordance with in the form of the 1951 Refugee Convention, and an international organization, the UNHCR, where it lies with the state concerned. However, we know there is administrative, security, financial and social problems but yet the government should not have imposed restriction on NGOs which speaks apathy on part of government. Following are few recommendations in order to reduce the burden of mental illness amongst IDPs which in turn will cause a diminution in social crimes and better society with healthy living — a rapid swift return of IDPs back to their homeland, homes, jobs, society and norms where peace prevails and normality exists.

1. IDPs from camps, who have returned to their homes / actual places of residence / who have resettled in another part of the country should not be discriminated as having been displaced. Humanitarian assistance to such IDPs should continue and not diverted, in particular for political or military reasons.

2. The national and the provincial governments' response strategies should include combination of bio-psycho-social health services, traditional medical practices, religion and faith and family and friends' support. Their management is often helped by supportive religious leaders / teachers who listen with kindness, trust and respect, which may contrast with usual practices in psychiatric diagnosis and medications. 3. Certain groups such as children especially unaccompanied minors, expecting mothers, mothers having young children, female who act as heads of household, persons with physical disabilities and elderly persons should be entitled assistance required as per their conditions and treatment which takes into account their specific needs. 4. Remedial interventions also include careful tailored re-socialization programs, behavior therapy, and environment enrichment.

5. All efforts should be exercised to revive financial aspects of the affected population returning back to their homes to avoid recurrence.

6. Reunion of families who got dispersed because of war or displacement, as quickly as possible. Appropriate properly focused steps to be taken for expediting the reunion of families, particularly when children or women are involved.

7. Anxiety and mistrust are common among conflict-zone residents. Every third person of Waziristan suffers from depressive disorders and number of women and children experience recurring nightmares of blood-splattered bodies and near dear ones of families living in destitution. Parental inhibition reduction, parental modeling, behaviorism, communication skills and problem-solving attitudes have also significant ways for Anxiety treatment.

8. Such vital is the social support which can even mitigate the negative impacts of unemployment and underemployment on individuals as well as families. Being married though is a protective factor during periods of unemployment/ underemployment but having large dependent family is at the same time risk factor for poorer mental health (Dooley \& Prause, 2004; McKee-Ryan et al., 2005). In one longitudinal study of men facing unemployment following plant closings, Gore (1978) found that men who had a lower level of support from wives, friends and relatives had worse health state as evident from self-reported illness symptoms and elevated cholesterol levels. $\mathrm{N}$ the same study those who blamed themselves for this unemployment were found more likely to report less level of social support. Social relationships which provide instrumental and emotional family support are found to be protective of mental fitness and life satisfaction among unemployed workers (McKee-Ryan et al., 2005). In contrast, "undermining" by family members (i.e. continous criticism, expressing anger or dislike because being 
Abdur Rahman Aleemi, Dr. Muhammad Tariq Chaudhry, Muhammad Azeem Qureshi, Dr. Roomana Anwar the unemployed individual) was found to be associated with degraded mental health among the unemployed (McKee-Ryan et al., 2005).

Finally to sum up, can we think and sum up the miseries of the victims of disasters happening there? Have a flight of your thoughts ....... Still won't be there to reach up what they are facing with-unimaginable with each breathe. But, let us think of how the event now amongst their new hosts may have affect of their system including mental health? Noteworthy that timing of the response is extremely important. Psychological impacts should be handled just at right time; otherwise; there is every chance that their impacts will disable the persons for years and societies for long. Techniques, skills and art is the need of time. Programs and research is required to address both short-term humanitarian relief and longer-term recovery situations, including deteriorating social behaviors. This study highlighted the link between trauma exposure and displacement as directly proportional to, depression, substance abuse and mental illnesses among conflict-affected displaced population of North Waziristan. The study also explored a linkage between negative community level influences of mental disorders. The findings of the study suggest many potential synergies for individual level and community level professional response for IDPs in general and the most vulnerable ones $\mathrm{n}$ particular.

\section{ACKNOWLEDGEMENT}

First of all with a profound gratitude, we are thankful to Almighty Allah forgiving us success, knowledge and understanding without which we would not been capable of completing this research paper.

We are also profoundly grateful to all our family members whose endurance and understanding have played a significant role in our success by sacrificing the important family time and supporting us all over the research work.

We are finally thankful to the editor, reviewers and IBT specially who provided us with the opportunity to publish our research paper in this esteemed journal.

\section{REFERENCES}

B. Roberts, K. Ocala, J. Browne, TOKyo, E. Sondorp, Factors associated with posttraumatic stress disorder and depression amongst internally displaced persons in northern Uganda, BMC Psychiatry, 8 (2008), p. 38

Bayard Roberts, Kaduku Felix Okaka, John Browne, Thomas Oyok and Egbert Sondorp. Factors associated with post-traumatic stress disorder and depression amongst internally displaced persons in northern Uganda.BMC Psychiatry 2008, 8:38 doi: 10.1186/1471-244X-

Bayard Roberts, Vicky Norah Odong, John Browne, Kaduku Felix Okaka, Wenzel Geissler and Egbert Sondorp. An exploration of social determinants of health amongst internally displaced persons in northern Uganda. Conflict and Health 2009, 3:10 doi: 10.1186/1

Bayard Roberts, EliabaYonaDamundu, Olivia Lomoro and Egbert Sondorp.Post-conflict mental health needs: a cross-sectional survey of trauma, depression and associated factors in Juba, Southern Sudan. BMC Psychiatry 2009, 9:7 doi: 10.1186/1471244X-9-7 
Psychological Vulnerabilities of Internally Displaced Persons in Pakistan and Its Effects on General Community

Bolton $\mathrm{P}$, et al.: Interventions for depression symptoms among adolescent survivors of war and displacement in northern Uganda: a randomized controlled trial.JAMA 2007, 298(5):519-27

Cindy Mel's, IlseDerluyn, Eric Broekaert and Yves Rosseel, The psychological impact of forced displacement and related risk factors on Eastern Congolese adolescents affected by war, Journal of Child Psychology and Psychiatry, Volume 51, Issue 10 , pages 109

Deng F: Report on the Representative to the Secretary-General on Internally Displaced Persons. 2002. UN Doc.E/CN.4/2002/95

Fawzi MC, et al.: The validity of posttraumatic stress disorder among Vietnamese refugees.Journal of Traumatic Stress 1997, 10(1):101-8

Human Rights Watch: Uprooted and Forgotten: Impunity and Human Rights Abuses in Northern Uganda. Human Rights Watch: New York; 2005

IASC (2007) IASC Guidelines on Mental Health and Psychosocial Support in Emergency Settings. Geneva: IASC

Interventions for Depression Symptoms Among Adolescent Survivors of War and Paul Bolton, Judith Bass, Theresa Betancourt, LiesbethSpeelman, Grace Onyango, Kathleen F. Clougherty, MSW; Richard Neugebauer, PhD; Laura Murray; Helen Verdeli,Displacement in Northern UgandaA Randomized Controlled Trial, JAMA. 2007; 298(5):519-527. doi:10.1001/jama.298.5.519

Johnson H, Thompson A: The development and maintenance of post-traumatic stress disorder (PTSD) in civilian adult survivors of war trauma and torture: A review.Clinical Psychology Review 2008, 28(1):36-47

Lopes Cardozo B, et al. Mental health, social functioning, and disability in postwar Afghanistan.JAMA 2004, 292(5):575-84

Lopes Cardozo B, et al.: Mental health, social functioning, and attitudes of Kosovar Albanians following the war in Kosovo. JAMA 2000, 284(5):569-77

M.C.S. Fawzi, T. Pham, L. Lin, T.V. Nguyen, D. Ngo, E. Murphy, R.F. Mollica, The validity of posttraumatic stress disorder among vietnamese refugees, J. Trauma. Stress, 10 (1) (1997), pp. 101-108

Mollica RF, Caridad KR, Massagli MP: Longitudinal study of posttraumatic stress disorder, depression, and changes in traumatic memories over time in Bosnian refugees.JNervMent Dis 2007, 195(7):572-9

MSF-Holland: [http://www.msf.or.jp/news/baseline/Baseline.pdf]Internally Displaced Camps in Lira and Pader, Northern Uganda. A Baseline Health Survey. Preliminary Report. 2004

Paul Bolton, Judith Bass, Theresa Betancourt, LiesbethSpeelman, Grace Onyango, Kathleen F. Clougherty, Richard Neugebauer, Laura Murray, Helen Verdeli.Interventions for Depression Symptoms Among Adolescent Survivors of War and Displacement in Northern UgandaA Randomized Controlled Trial. JAMA. 2007; 298(5):519-527. doi:10.1001/jama.298.5.519

Porter M, Haslam N (2005) Pre Displacement and post displacement factors associated with mental health of refugees and internally displaced persons: a meta-analysis. Journal of the American Medical Association 294: 602-612. doi: 10.1001/jama.294.5.602

R. Mollica, K. McInnes, N. Sarajlic, J. Lavelle, I. Sarajlic, M. Massagli, Disability associated with psychiatric comorbidity and health status in Bosnian refugees 
Abdur Rahman Aleemi, Dr. Muhammad Tariq Chaudhry, Muhammad Azeem Qureshi, Dr. Roomana Anwar living in Croatia, JAMA, 282 (1999), pp. 433-439

Rapid assessment of IDPs in host communities in Mardan and Swabi Districts., Save the Children Alliance, May 31, 2009, (http://www.reliefweb.int/rw/rwb.nsf/db900sid/MINE- 7SQ4K4 Roberts B, Murphy A, Chikovani I, Makhashvili N, Patel V, et al ,Factors associated with post-traumatic stress disorder and depression amongst internally displaced persons in northern Uganda, BMC Psychiatry 2008, 8:38 doi: 10.1186/1471244X-8-38

Roberts B, Murphy A, Chikovani I, Makhashvili N, Patel V, et al. (2014) Individual and Community Level Risk-Factors for Alcohol Use Disorder among ConflictAffected Persons in Georgia. PLoS ONE 9(5): e98299. Doi: 10.1371/journal. Published: May 27, 2014

Further Readings:

State of Human Rights in 2007, p. 203, Human Rights Commission of Pakistan, 2008 Swat: Paradise Regained?, p. 24, Human Rights Commission of Pakistan, July 2010 , (www.hrcp-web.org/pdf/SwatParadise-Regained.pdf

Taylor, P. J.; Gunn, J. (1999). "Homicides by people with mental illness: Myth and reality". The British Journal of Psychiatry 174: 9-14. doi:10.1192/bjp.174.1.9

UNHCR (2013) Operational Guidance Mental Health \& Psychosocial Support Programming for Refugee Operations. Geneva: UNHCR

UNHCR WHO (2008) Rapid assessment of alcohol and other substance use in conflictaffected and displaced populations. Geneva: United Nations High Commissioner

for Refugees/World Health Organisation

UNICEF: Children and women displaced by conflict in Pakistan need urgent and ongoing support, July 3, 2009, (http://www.unicef.org/pakistan/media_5245.htm

W. Kleijn, J. Hovens, J. Rodenburg, Posttraumatic stress symptoms in refugees assessments with the Harvard Trauma Questionnaire and the Hopkins symptom checklist-25 in different languages, Psychol. Rep., 88 (2) (2001), pp. 527-532

Weller M.P.I. and Eysenck M. The Scientific Basis of Psychiatry, W.B. Saunders, London, Philadelphia, Toronto etc. 1992

WHO (2011) Global status report on alcohol and health. Geneva: World Health Organization. 


\section{ANNEXURE}

\section{Table 1: Demographic Distribution of the Participants.}

\begin{tabular}{|c|c|c|c|c|c|}
\hline S.No & Identity & \begin{tabular}{|l}
$\begin{array}{l}\text { Age } \\
\text { (years) }\end{array}$ \\
\end{tabular} & Sex & Native Place & $\begin{array}{l}\text { Diagnosed with } \\
\text { Disease at (See } \\
\text { Table 2) }\end{array}$ \\
\hline 1 & JUMMA KHAN & 28 & MALE & Data Khel & Serial 3 \\
\hline 2 & SHAZIA KHAN & 34 & FEMALE & Mir Ali & Serial 1 \\
\hline 3 & ANNAR KHAN & 11 & CHILD & Ghulam Khan & Serial 7 \\
\hline 4 & DARYA KHAN & 51 & MALE & Birmal & Serial 6 \\
\hline 5 & NAJMA SHAHEEN & 19 & FEMALE & Miran Shah & Serial 4 \\
\hline 6 & GULAB JAN & 29 & MALE & Serwekai & Serial 3 \\
\hline 7 & SPEEN GUL & 10 & CHILD & Saraogha & Serial 7 \\
\hline 8 & GUL KHAN & 48 & MALE & Tiarza & Serial 6 \\
\hline 9 & SHARAFAT KHAN & 36 & MALE & Garyum & Serial 8 \\
\hline 10 & KAINAT BIBI & 18 & FEMALE & Miran Shah & Serial 2 \\
\hline 11 & DILAWAR KHAN & 34 & MALE & Razmak & Serial 7 \\
\hline 12 & PALWA ZEB & 22 & FEMALE & Razmak & Serial 4 \\
\hline 13 & MALALA & 12 & CHILD & Serwekai & Serial 7 \\
\hline 14 & SHAHBAZ KHAN & 38 & MALE & Birmal & Serial 7 \\
\hline 15 & AISHA GULALAI & 72 & FEMALE & Birmal & Serial 1 \\
\hline 16 & AFIA YOUSAF ZAI & 41 & FEMALE & Mir Ali & Serial 2 \\
\hline 17 & LAL FARAZ KHAN & 31 & MALE & Mir Ali & Serial 4 \\
\hline 18 & GHULFAM & 14 & CHILD & Serwekai & Serial 5 \\
\hline 19 & SHAISTA REHMAN & 19 & FEMALE & Saraogha & Serial 4 \\
\hline 20 & HAALA KHAN & 23 & FEMALE & Makin & Serial 3 \\
\hline 21 & WALI KHAN & 29 & MALE & Razmak & Serial 10 \\
\hline 22 & HASHMAT BIBI & 23 & FEMALE & Birmal & Serial 2 \\
\hline 23 & BRASHNA KHAN & 55 & FEMALE & Mir Ali & Serial 7 \\
\hline 24 & MEEZAR KHAN & 51 & MALE & Data Khel & Serial 7 \\
\hline 25 & WALI UR REHMAN & 32 & MALE & Ghulam Khan & Serial 3 \\
\hline 26 & NOOR WALI & 35 & MALE & Serwekai & Serial 4 \\
\hline 27 & BLONCHEH & 29 & FEMALE & Mir Ali & Serial 4 \\
\hline 28 & RUBAB KHAN & 67 & FEMALE & Saraogha & Serial 1 \\
\hline 29 & SHER GUL & 42 & MALE & Miran Shah & Serial 6 \\
\hline 30 & GULREZ KHAN & 49 & MALE & Ladha & Serial 9 \\
\hline 31 & HABIB KHAN & 44 & MALE & Mir Ali & Serial 7 \\
\hline 32 & KASHMALA & 39 & FEMALE & Serwekai & Serial 9 \\
\hline 33 & JAAH KHAN & 64 & MALE & Razmak & Serial 4 \\
\hline 34 & INDEELA KHAN & 27 & FEMALE & Dossali & Serial 2 \\
\hline 35 & IMZAA KHAN & 41 & FEMALE & Data Khel & Serial 7 \\
\hline 36 & IBTIHAJ KHAN & 43 & MALE & Ghulam Khan & Serial 8 \\
\hline 37 & SHER KHAN & 56 & MALE & Razmak & Serial 7 \\
\hline 38 & PARIGUL KHAN & 15 & CHILD & Data Khel & Serial 3 \\
\hline 39 & NAYAB KHAN & 62 & FEMALE & Ghulam Khan & Serial 2 \\
\hline 40 & PARWISH KHAN & 34 & FEMALE & Mir Ali & Serial 6 \\
\hline 41 & MASHAAL KHAN & 15 & CHILD & Ladha & Serial 4 \\
\hline 42 & MUHABBAT KHAN & 59 & MALE & Ladha & Serial 4 \\
\hline 43 & NAHAL KHAN & 22 & FEMALE & Birmal & Serial 4 \\
\hline 44 & MAHTA KHAN & 54 & FEMALE & Mir Ali & Serial 10 \\
\hline 45 & MALLALAI KHAN & 72 & MALE & Makin & Serial 1 \\
\hline 46 & ANGAR KHAN & 43 & MALE & Razmak & Serial 7 \\
\hline 47 & ANJEZA & 13 & CHILD & Tiarza & Serial 5 \\
\hline 48 & AZLAN & 64 & FEMALE & Serwekai & Serial 4 \\
\hline 49 & GHONCHEH & 24 & MALE & Saraogha & Serial 3 \\
\hline 50 & AMAIL BIBI & 23 & FEMALE & Data Khel & Serial 9 \\
\hline 51 & NAWAB KHAN & 60 & MALE & Saraogha & Serial 3 \\
\hline 52 & IBTESAMA & 35 & MALE & Miran Shah & Serial 7 \\
\hline 53 & JEHANZAIB KHAN & 11 & CHILD & Ladha & Serial 2 \\
\hline 54 & HILMI & 31 & MALE & Garyum & Serial 10 \\
\hline 55 & AFROZEH & 64 & FEMALE & Dossali & Serial 4 \\
\hline 56 & ABASIN KHAN & 43 & MALE & Makin & Serial 9 \\
\hline 57 & AEEDAH KHAN & 32 & FEMALE & Ghulam Khan & Serial 7 \\
\hline 58 & TIRDAD KHAN & 35 & MALE & Razmak & Serial 7 \\
\hline 59 & UZBIK KHAN & 26 & MALE & \begin{tabular}{|l|} 
Data Khel \\
\end{tabular} & Serial 4 \\
\hline 60 & ZOONA KHAN & 53 & FEMALE & Razmak & Serial 10 \\
\hline 61 & ZINIA KHAN & 32 & FEMALE & Mir Ali & Serial 2 \\
\hline 62 & ITWAR KHAN & 34 & MALE & Dossali & Serial 6 \\
\hline 63 & ZAYBA KHAN & 12 & CHILD & Serwekai & Serial 2 \\
\hline 64 & WOWREENA & 46 & FEMALE & Data Khel & Serial 3 \\
\hline 65 & VANDA KHAN & 58 & FEMALE & Razmak & Serial 10 \\
\hline 66 & WALAYAT ULLAH & 41 & MALE & Mir Ali & Serial 10 \\
\hline 67 & SHAGUFTA & 35 & FEMALE & Miran Shah & Serial 7 \\
\hline 68 & SHANDANA & 22 & FEMALE & Saraogha & Serial 4 \\
\hline 69 & DOWLAT KHAN & 61 & MALE & Birmal & Serial 9 \\
\hline 70 & SHAHZAR & 27 & MALE & Serwekai & Serial 7 \\
\hline 71 & SOHRAB KHAN & 35 & MALE & Miran Shah & Serial 3 \\
\hline 72 & SHARJEELA & 12 & FEMALE & Ghulam Khan & Serial 2 \\
\hline 73 & HAKEEM KHAN & 22 & MALE & Saraogha & Serial 10 \\
\hline 74 & NAJEEBULLAH & 64 & MALE & Birmal & Serial 1 \\
\hline 75 & M.IHSAN & 09 & CHILD & Mir Ali & Serial 7 \\
\hline 76 & DUI KHAN & 21 & MALE & Mir Ali & Serial 5 \\
\hline 77 & NOORULLAH & 36 & MALE & Serwekai & Serial 4 \\
\hline 78 & GHULAM NABI & 71 & MALE & Saraogha & Serial 3 \\
\hline 79 & HASEENA & 32 & FEMALE & Serwekai & Serial 2 \\
\hline 80 & $\begin{array}{l}\text { TAYYAB } \\
\text { MUHAMMAD }\end{array}$ & 13 & CHILD & Data Khel & Serial 3 \\
\hline 81 & ARSHAD KHAN & 51 & MALE & Mir Ali & Serial 10 \\
\hline 82 & NAWAZ KHAN & 44 & MALE & Saraogha & Serial 7 \\
\hline 83 & FASADULLAH & 28 & MALE & Birmal & Serial 4 \\
\hline 84 & NAJEEBAH & 32 & FEMALE & Serwekai & Serial 9 \\
\hline 85 & ZUJEJA & 14 & CHILD & Miran Shah & Serial 7 \\
\hline 86 & ROOMANA KHAN & 41 & FEMALE & Ghulam Khan & Serial 9 \\
\hline 87 & MOULVI DIN KHAN & 25 & MALE & Miran Shah & Serial 7 \\
\hline 88 & IMRAN KHAN & 31 & MALE & Ladha & Serial 3 \\
\hline 89 & HUNAIZA & $\frac{\pi}{12}$ & CHILD & Garyum & \begin{tabular}{|l|} 
Serial 7 \\
\end{tabular} \\
\hline
\end{tabular}




\begin{tabular}{|l|l|l|l|l|l|}
\hline 90 & ATTA MUHAMMAD & 37 & MALE & Mir Ali & Serial 10 \\
\hline 91 & HIDAYAT ALI & 53 & MALE & Garyum & Serial 2 \\
\hline 92 & SHER KHAN & 33 & MALE & Miran Shah & Serial 3 \\
\hline 93 & M.NOOR & 31 & MALE & Razmak & Serial 7 \\
\hline 94 & GEEGA KHAN & 17 & MALE & Razmak & Serial 2 \\
\hline 95 & GULZEB BIBI & 23 & FEMALE & Mir Ali & Serial 10 \\
\hline 96 & AUN KHAN & 45 & MALE & Dossali & Serial 4 \\
\hline 97 & ALF KHAN & 58 & MALE & Serwekai & Serial 9 \\
\hline 98 & SAEEDULLAH & 26 & MALE & Ghulam Khan & Serial 1 \\
\hline 99 & AZIZA & 11 & CHILD & Razmak & Serial 2 \\
\hline 100 & ALI KHAN & 31 & MALE & Data Khel & Serial 4 \\
\hline 101 & KHAULA & 23 & FEMALE & Data Khel & Serial 5 \\
\hline 102 & ABID AHMED & 37 & MALE & Mir Ali & Serial 3 \\
\hline 103 & TOTEE KHAN & 53 & MALE & Miran Shah & Serial 3 \\
\hline
\end{tabular}

Table 2: Psychological issues faced by IDPs

\begin{tabular}{|c|c|c|c|}
\hline S. No & DISEASE DIAGNOSED WITH & NUMBER/103 & $\%$ \\
\hline 1 & Emotional perception / sense of having lost freedom & 6 & 5.8 \\
\hline 2 & Displacement causing Behavior changes & 12 & 11.7 \\
\hline 3 & $\begin{array}{l}\text { Anxiety Disorders -social anxiety disorder, panic } \\
\text { disorder, generalized anxiety disorder, specific } \\
\text { phobias, agoraphobia, obsessive-compulsive disorder }\end{array}$ & 15 & 14.6 \\
\hline 4 & $\begin{array}{l}\text { Mood disorder -Manic depression which involves } \\
\text { abnormally "high" mood states, called Mania or } \\
\text { Hypomania, unusually intense and sustained sadness } \\
\text { or despair called Major depression, alternating with } \\
\text { normal or depressed mood }\end{array}$ & 18 & 17.5 \\
\hline 5 & $\begin{array}{l}\text { Various new types of mental disorders - sadistic } \\
\text { personality, self-defeating personality, passive- } \\
\text { aggressive personality disorder }\end{array}$ & 4 & 3.9 \\
\hline 6 & A mixed anxiety and depression-like syndrome & 6 & 5.8 \\
\hline 7 & $\begin{array}{l}\text { Post-traumatic stress disorder (hopelessness, constant } \\
\text { crying, over thinking) }\end{array}$ & 22 & 21.4 \\
\hline 8 & $\begin{array}{l}\text { Psychotic disorders include schizophrenia and } \\
\text { delusional disorder }\end{array}$ & 2 & 1.8 \\
\hline 9 & $\begin{array}{l}\text { Other Personality disorders including paranoid and } \\
\text { schizoid. "Emotional" states likehistrionic or } \\
\text { narcissistic personality, antisocial, borderline }\end{array}$ & 8 & 7.8 \\
\hline 10 & $\begin{array}{l}\text { Sleep disorders like insomnia which involves } \\
\text { disruption of normal sleep patterns, or subjective } \\
\text { feeling of tiredness despite normal sleep }\end{array}$ & 10 & 9.7 \\
\hline
\end{tabular}


Table 3: Increase in crimes. Source; local police stations collected by the authors

\begin{tabular}{|l|l|c|}
\hline S.No & CRIME & OBSERVED INCREASE \\
\hline 1 & Thieving & +++ \\
\hline 2 & Reproduction of violence in the home & +++ \\
\hline 3 & Use of non custom paid vehicles & +++ \\
\hline 4 & Prostitution & + \\
\hline 5 & Use of Narcotics & +++ \\
\hline 6 & $\begin{array}{l}\text { Kidnapping of women, children, specific targets } \\
\text { and kidnapping for ransom }\end{array}$ & + \\
\hline 7 & Homosexuality & ++ \\
\hline 8 & Violence & + \\
\hline 9 & Street crimes & + \\
\hline 10 & Homicide & + \\
\hline 11 & Suicide & ++ \\
\hline 12 & Illegal arms & + \\
\hline 13 & Gambling & + \\
\hline
\end{tabular}

Table 4: Legend for table 3

\begin{tabular}{|l|l|}
\hline+ & Slight increase, from 1-10\% \\
\hline++ & Moderate increase, from 11-25\% \\
\hline+++ & Significant increase, from 26-50\% \\
\hline++++ & Massive in crease, greater than 50\% \\
\hline
\end{tabular}

\section{QUESTIONAIRRE}

Q.1 Where do you come from (place of origin)?

Q.2 When did you migrate?

Q.3 What wereyour economical condition in your native place?

Q.4 What are the family members do you have?

Q.5 What caused you to leave your native place?

Q.6 Could not have you survived even when most others had migrated your native place?

Q.7 What is and was your source of income?

Q.8 How did you manage to reach the present living?

Q.9 Do you presently have family all living together? Enough accommodation?

Q.10 Are you satisfied with how you are being taken care here?

Q.11 Are you in perfect state of health?

Q.12 What do you think your symptoms are related to?

Q.13 Do you think you require medication / specialist doctor for your illness?

Q.14 Do you have any previous history of illness?

Q.15 How would you describe the health of people around you?

Q.16 Have you or any of your family member being ever interrogated by police? Whatfor?

Q.17What are the factors that are affecting your health n IDP camps?

Q.18 How have these things managed to affect your health?

Q.19 Why do you think that these things have adverse effects on your health? 